\title{
'Add Twitter and Stir': The Use of Twitter by Public Authorities in Norway and UK during the 2014-15 Ebola outbreak ${ }^{1}$
}

\author{
Colin John McInnes*, Harald Hornmoen** \\ *Professor, Aberystwyth University, UK \\ **Professor, Oslo Metropolitan University
}

\begin{abstract}
This article examines how Norwegian and UK health authorities used social media, and especially Twitter, during the 2014-15 Ebola outbreak. The microblogging service has been regarded as a promising medium for crisis communicators due to its immediacy and dialogical potential. Twitter allows communicators to respond directly to users' concerns and provide them with more precisely tailored information. However, scholars have raised questions over organizations' ability to respond to the the medium. We address these questions in two ways: 1 . we examine the social media strategies adopted by the health authorities at the time of the outbreak. 2. we conduct an analysis of tweets produced by health authorities concerning the Ebola outbreak. Our analyses display some differences between UK and Norwegian authorities in terms of the strategies they adopted and the tweets they produced. However, neither country fully exploited Twitter's dialogical potential. Both countries authorities preferred a vertically integrated approach with minimal opportunities for the public to engage and little monitoring of the wider Twitter 'conversations'. We conclude that the emergence of social media has not led to a paradigm shift in crisis communication for these countries' health authorities, rather to an evolution and adaption of practices and policies.
\end{abstract}

Keywords: Ebola, Crisis communication, Social media, Twitter, Health authorities

\section{Introduction}

Twitter has become ubiquitous in many high income countries (HICs, see Mocanu et al, 2013), users ranging from politicians (including of course Donald Trump) to pop stars, from traditional media outlets to new, largely unregulated sources of news and opinion, and of course the general public. Although as a communication tool it can be used for a variety of purposes and on differing occasions, this article examines its use in crisis situations. For its advocates, Twitter offers risk and crisis communicators advantages in immediacy and tailored response authorities can directly monitor and respond to users' concerns. Moreover, given the numbers of professionals and the general public who use Twitter as a source of news, opinion and information, so crisis communicators need to engage with this technology if they are to control the narrative and convey what may be important ultimately in saving lives. However, Valentini and Kruckeberg $(2016,482)$ observe that social media such as Twitter have 'raised questions about how organizations can prepare for critical situations, managing and even exploiting... capabilities for interactivity and dialog in crisis communication'. In this article we examine public authorities' use of Twitter during a particular form of crisis - disease outbreaks, focusing particularly on the 201415 Ebola crisis [1], to test this observation. Over the past two decades, the fear of communicable diseases

\footnotetext{
1 This research is part of the project Researching Social Media and Collaborative Software Use in Emergency Situations
} (RESCUE), funded by The Research Council of Norway (grant no. 233975/H20).

Copyright (c) 2018 (Colin John McInnes \& Harald Hornmoen). Licensed under the Creative Commons AttributionNonCommercial Generic (cc by-nc). Available at http://obs.obercom.pt. 
spreading and affecting HICs has emerged as a major policy concern (DoH, 2008; FCO, 2003, 13; State Department, 2004, 76). In this narrative, a major outbreak of a communicable disease is of global concern given its potential to spread to any part of the world. Moreover, understandings of risk suggest that individual and societal fear over a disease may be unrelated to epidemiological considerations (ie how the disease is spread and the probability of infection) and instead reflect perceptions of vulnerability (ie the possibility and consequences of infection) (Durodie, 2011; Furedi, 2008). Therefore, a major disease outbreak such as that of Ebola in West Africa is considered a global event with implications for countries outside the region, while the medical evacuation and emergence of cases in the US and Europe prompted a widespread sense of risk among Western populations late in 2014, seen not least in the massive spike in social media interest (Luckerson, 2014). A key element in responding to such crises is effective communication by authorities, both to reassure the public and to offer advice on how to avoid infection. We discuss how public health authorities in two HICs, Norway and the UK, have developed plans for using social media during disease outbreaks and how one key social media platform - Twitter - was used by Norwegian and UK health authorities during the 2014-15 West African Ebola outbreak. We argue that crisis communicators in health emergencies have demonstrated a preference for developing established communications methodologies to incorporate social media, rather than radical change an approach which may be characterised as 'add Twitter and stir'. ${ }^{[2]}$ We also argue that Norway has proved more adaptable to the new technology, suggesting that Valentini and Kruckeberg's observation requires more nuance.

The extent to which the 2014-15 Ebola epidemic really was a health crisis for the UK and Norway is contestable given the extremely small number of cases, none of which were contracted in these countries - though as as the Director of the WHO, Margaret Chan, commented 'In my long career in public health... I have never seen a health event strike such fear and terror, well beyond the affected countries' (Chan, 2015). Whereas the word "crisis" denotes "crucial change" and crises typically are understood as events that can impair societies' ability to function (Johansen \& Frandsen 2007), a "risk" does not refer to a change that has occurred, rather to "the chance or possibility of danger (harm, loss, injury and so forth) or other adverse consequences actually happening" (Allan 2002: 209). We acknowledge that - despite the WHO declaring the Ebola outbreak a Public Health Emergency of International Concern, only the third time it had triggered this highest state of alert (WHO, 2014) - the Ebola crisis does not squeeze easily into the category of crisis communication. In the UK and Norway, communicative measures taken towards own country citizens barely reached the level of precaution advocacytrying to arouse concern and motivate preparedness - and did not involve communication typical of a crisis stage of infectious diseases, such as helping people to bear the outbreak and guide them through it (see Sandman 2014 on these stages). However, the term 'crisis communication' conventionally ecompasses all possible stages of a crisis, including a pre-crisis stage (Coombs 2012), or what may be seen as a risk stage of an infectious disease. Given this, and the high level of perceived risk, the Ebola outbreak allows us to examine how crisis authorities have used this new medium and in particular its use over a 'long wave event' - whereas crises such as a major fire or terrorist incident may be over within a few hours, the Ebola crisis lasted several months. 


\section{Literature review, social media in crisis communication}

Research draws attention to how social media change conditions for crisis communication (Coombs, 2012; Utz, Schultz, \& Glocka, 2013; Veil et al. 2011; Simon, Goldberg, Aharonson-Daniel, Leykin, \& Adini, 2014; Hagen, Keller, Neely, DePaula, \& Robert-Cooperman, 2017; Hornmoen et al. 2018). These studies point to the increasing use of social media in the population, and social media's accessibility and immediacy. Social media can speed up the dissemination of information during crises by linking end users to critical information sources in real-time. Hughes and Palen (2012) and Latonero and Shklovski (2011) are among several studies that show how social media allow public health officials to communicate directly with the public, thus eliminating the time it takes for emergency information and advice to flow through traditional communication channels.

A crucial innovation of social media is that public users as much as authorities control the creation and distribution of information (eg Coombs, 2012). Moreover, social media are dialogical in nature and horizontally networked rather than the more traditional vertical (albeit sometimes bi-directional) structures of emergency communication (eg Schultz et al., 2011; Utz et al., 2012; Veil et al., 2011). The advent of social media therefore appears to require crisis communicators to adjust their practices if they are to communicate effectively. The established, vertically-integrated model is of health authorities gathering epidemiological data and using this to provide health professionals and the public with information in a coordinated and coherent manner (for example, DoH, 2012). In contrast, social media create both vertical and horizontal connections, allow crisis communicators to listen and respond to what users are saying, and provide them with the ability to tailor information to users' concerns. However, we argue that both in their plans and in practice, Norway and the UK largely saw the medium in terms of a traditional paradigm of crisis communication usage - namely that crisis communication is to provide the public with that information which is deemed necessary. In so arguing, we develop on the findings of related research (for example, Perry, Taylor, and Doerfel, 2003; Sutton, Palen, and Shklovsky, 2008; Thackeray et al., 2012), which suggest that health crisis communicators have found the paradigm-shifting capacity of social media difficult to manage. We argue that this might not simply be the product of organisational conservatism, but reflects other phenomena, including a lack of capacity to engage in the dialogical potential of social media and the difficulties authorities face in responding to comments given that these are official pronouncements requiring authorisation. Nevertheless, we question the effectiveness of authorities' use of social media in that reaction to authorities' tweets during the Ebola crisis (measured by numbers of posted likes and re-tweets) was surprisingly low. This builds on the findings of Thackeray et al. (2012), which suggested that public health authorities in the UK had not developed a strong presence amongst Twitter users. We nuance this by arguing the number of likes/re-tweets was broadly in line with other popular news communicators, but note that it was significantly lower than celebrities and 'social media stars' tweeting on Ebola.

In public health, interest in social media has focussed on its surveillance potential: monitoring social media activity may allow authorities to detect outbreaks at an early stage and minimise their spread (e.g. Bernardo et al., 2013; Aramaki, Maskawa, and Morita, 2011; Lamb, Paul, and Dredze, 2013; Paul and Dredze, 2011; though see also debate over limits of web based proxies, e.g. Olson et al., 2013). However, our focus is on the less 
studied question of its use as a risk and crisis communication tool: that is, how it might be used to inform and reassure the public. Not least, social media may be quicker than established media, may be able to reach different user groups or reinforce messaging from other sources, and may provide sentiment analysis allowing authorities to reduce fear and anxiety. Relevant to this, Chew \& Eysenbach (2010) concluded from a content analysis of tweets during the $2009 \mathrm{H} 1 \mathrm{~N} 1$ outbreak that these provided a rich source of opinions and experiences which can be used for real-time content and sentiment analysis, allowing health authorities to better respond to public concerns.

\section{Research design}

Although the first identified case of Ebola in West Africa was traced back to December 2013, the crisis is usually seen as beginning with the WHO's announcement of an outbreak at the end of March 2014 (McInnes, 2016). The Norwegian health authorities, however, prioritized tweeting about Ebola only in a short period towards the end of 2014. They initially posted 9 tweets from 31 July to 26 August in a period following the declaration by MSF (Médecins Sans Frontières) that the second wave of Ebola was out of control, and WHO's declaration of Ebola as an international health emergency. However, it was not until MSF announced that an affected Norwegian working for them - Silje Lehne Michalsen - was to be med-evaced to Norway (6 October) that the health authorities markedly increased their postings. For closer analysis we recorded tweets that were posted during their most active period for communicating about Ebola, namely between 6 October and 17 November. In this period, the authorities posted 28 tweets.

In the UK, the first tweets from public health authorities were in late July/early August, when two US aid workers were med-evaced to specialist facilities in Texas. These tweets were simple redirects to statements outlining the UK government's ongoing response to the emerging crisis in West Africa. The first UK med-evacuation (Will Pooley on 24 August) did not lead to any tweets by the Department of Health ( $\mathrm{DoH}$, the lead government agency for communications during an outbreak), the next being on 19 September (again a redirect, advising NHS staff interested in volunteering for West Africa). Activity picked up during October and November, mainly commenting on the low risk to UK citizens and on the UK's response to the crisis (including the deployment of UK military assets); but the level of activity remained low, with usually just 1-2 tweets per week. This changed with the diagnosis of the Scottish nurse Pauline Cafferkey at the end of December. Cafferkey had left West Africa for the UK, catching an internal flight from London to Glasgow before being diagnosed with Ebola. On 29 December alone, the DoH posted 7 tweets on its main account (@DHgovuk), many from the Chief Medical Officer Sally Davies reassuring the public over the low risk. Activity however soon dropped after this spike, returning during January 2015 to the average of 1-2 per week. Our analysis of UK tweets therefore covers the period from the first tweets in July 2014 on the DoH's main account (@DHgov.uk) to the end of January 2015.

Our initial focus on Norway expanded to include the UK to offer a comparative element. Our choice of case studies was influenced by the following factors: both are HICs for whom outbreaks of deadly diseases are novel risks; both are liberal democracies, with well-established traditions of freedom of speech and expression reflected 
in their use of social media; both have high Twitter usage; and both countries had nationals med-evaced home from West Africa infected with Ebola. By offering a comparison between two similar countries, we may speculate more freely about whether the approaches to and issues with Twitter's use by authorities are specific to Norway or perhaps more generic to HICs. We focus on Twitter as (with Facebook) one of the two most popular social media platforms at the time of Ebola. And we use the West African Ebola outbreak as our test for disease outbreaks because by then social media use by the general public was well established (Guardian, May 15, 2012 and February 20, 2014; Ipsos, April 18, 2016. http://ipsos-mmi.no/some-tracker) and crisis communication plans for social media were in place, unlike during the 2009 'swine flu' outbreak (compare for example Clayforth-Carr 2009 and PHE 2015a).

In Norway, we focus on the plans and practices of two key governmental agencies - The Norwegian Directorate of Health (NDH, our abbreviation) and The Norwegian Institute for Public Health (NIPH). The Directorate is responsible for monitoring conditions that affect public health and trends within the health and care services, and acts as the national normative and expert body on health matters, giving 'independent and impartial advice'. The Norwegian Institute of Public Health (NIPH) works to improve public health by strengthening the preventive health efforts in society, and it has an overall responsibility for knowledge production and systematic reviews for the health sector. It provides knowledge and recommendations for governmental authorities, the health service, politicians, the media and the general public. In the UK, we focus on the Department of Health (DoH) which was the lead agency for communications policy during health emergencies (UK Government, 2015); and Public Health England (PHE), which provided technical advice and expertise on epidemics. In the UK, health is a devolved responsibility which means that Scotland and Wales both have separate health agencies, though the London government represents the UK internationally and is the contact point for global emergencies. Since there were no cases of Ebola in Wales, and since the only one case in Scotland was quickly moved to specialist care in London, we have not focused on them.

The paper has two main objectives. The first (addressed in 'Results and Analysis 1 ') is to examine the policies and strategies Norway and the UK had established by the time of the Ebola outbreak for the use of social media during health emergencies. Since both countries' policies concern social media in general, rather than addressing Twitter in particular, the discussion here is similarly more general. Specifically, we ask:

Q1.1: What importance was attached by public health authorities to social media?

Q1.2: Given the pluralist nature of discussion on social media, what importance was attached by public health authorities to gaining trust in their social media posts and being seen as the authoritative source of information; and how did authorities in the UK and Norway attempt to generate this trust?

Q1.3: How did authorities address the interactive nature of social media - to what extent were their strategies 'top down', bi-directional or horizontally networked?

The second objective (addressed in 'Results and Analysis 2') is to conduct a preliminary analysis of the tweets produced by the UK and Norwegian authorities concerning Ebola, to determine how Twitter was actually used. 
We focus upon the nature of the content, who the tweets were directed at, the discourse form and dominant speech act, and use proxy measures ('likes' and re-tweets) to infer impact and effectiveness.

\section{Methods and material}

We obtained data from primary source documents, key informant interviews and the Twitter archive. In Norway, we used primary source documents from the governmental health agencies. These included a national contingency plan against Ebola (NHD \& NIPH, 2014), descriptions of strategic measures for risk and crisis communication (NHD, 2015a), .ppt-presentations for health professionals on social media usage in the health directorate, documents on action plans for tackling epidemics and pandemics presented at a High Level Policy Forum (NHD, 2015b) in Europe, as well as notes on lessons learned for public health from the Ebola outbreak concerning communication strategies (NHD, 2016). In the UK, Freedom of Information (FOI) requests across multiple government Departments and Agencies revealed that key documents mainly originated with the DoH and PHE. Some of these were already publicly available, but others were only made available through successive FOI requests. The documents used varied in their focus, from strategies for general health emergencies to more specific guidance for communication in pandemics and epidemics. The UK government's handling of the 2009 swine flu pandemic was the subject of a formal Review, which incorporated an assessment of the use of social media. Although the DoH conducted an internal review of its social media use during the Ebola crisis, this is exempt from FOI as it is deliberative rather than summative and therefore not currently available (DoH, 2016b). It is also perhaps noting that the use of social media during Ebola won a UK government communications award - suggesting it was seen by the government both as successful and worthy of wider commendation.

In Norway, semi-structured interviews were conducted with the communications directors at the NDH, and the NIPH. ${ }^{[3]}$ Their communications departments have the primary responsibilities within their institutions for all activities in social media, including responding to all questions that come in, monitoring and analyzing social media, assessment of new social media channels and pages, and crisis communication. Semi-structured interviews were also used in the UK with public health authorities, though anonymity was requested. As a result we developed a different strategy of using FOI requests to ask direct questions which, where appropriate, were followed up with supplementaries. These provided us with 'on the record' responses to questions.

For Twitter, we searched for tweets using the term 'Ebola' or 'ebola' posted by the two key Norwegian health authorities, the NDH, and the NIPH (@Helsedir and @Folkehelseinst). UK twitter data was collected by searching the DoH's main Twitter account (@DHgovuk) with the same term. ${ }^{[4]}$ To analyse tweets, we identified topics and content types, including the discourse forms and speech acts (Searle, 1975; Vosoughi \& Roy, 2016; Zhang et.al., 2011), according to linguistic indication of:

1. addressees as either general twitter users (e.g.: 'We have just posted updated questions and answers about \#ebola', followed by an internet address) or health professionals ('Are you health personnel and do you want ebola-information? Check out our page:', followed by address). 
2. Discourse form: is the tweet mainly an announcement (a public notification), an instruction (an instance of verbally directing or guiding users), a report (an account of an event or statement for example in the form of a quotation from a health professional's media appearance, with attribution to this person) or something else (a question, for example).

3. Dominant speech acts in each tweet were determined according to the following definitions: Constatives (an utterance that asserts or states something that can be judged as true or false), Directives (utterances that are to cause the addressee to take a particular action, e.g. requests, commands and advice), Commissives (utterances that commit a speaker to some future action, e.g. promises), Expressives (utterances that express the speaker's attitudes and emotions towards the proposition, e.g. congratulations, excuses and thanks) (Searle 1975; Zhang et. al., 2011).

We also use 'likes' and 'retweets' as proxies for impact.

\section{Results and analysis 1: Strategy and policy}

This first part of the analysis schematizes and discusses the health authorities' strategies and policies for the use of social media in disease outbreaks, focusing especially on the Ebola outbreak. Three tables address in turn questions 1.1-1.3 identified above, using document analysis, and interviews and direct questions using FOI requests. 
Table 1: Importance attached to social media by Norwegian health and UK authorities.

\begin{tabular}{|c|c|c|c|c|}
\hline & $\begin{array}{l}\text { The Nor- } \\
\text { wegian } \\
\text { Director- } \\
\text { ate of Health }\end{array}$ & $\begin{array}{c}\text { Norwegian } \\
\text { Institute of } \\
\text { Public Health }\end{array}$ & $\begin{array}{c}\text { UK Department } \\
\text { of Health }\end{array}$ & $\begin{array}{c}\text { Public Health } \\
\text { England }\end{array}$ \\
\hline $\begin{array}{l}\text { Importance of social } \\
\text { media (SoMe) in } \\
\text { risk/ pandemic } \\
\text { communication }\end{array}$ & $\begin{array}{l}\text { SoMe considered } \\
\text { crucial in crisis } \\
\text { communi- } \\
\text { cation and } \\
\text { management } \\
\text { Facebook } \\
\text { emphasized, } \\
\text { Twitter somewhat } \\
\text { important } \\
\text { Facebook to be } \\
\text { used in preventive } \\
\text { measures, and to } \\
\text { recruit health } \\
\text { personnel }\end{array}$ & $\begin{array}{l}\text { SoMe seen as } \\
\text { very suited to } \\
\text { give people } \\
\text { enough } \\
\text { information to } \\
\text { make good } \\
\text { assessments } \\
\text { during risks } \\
\text { Twitter } \\
\text { emphasized, FB } \\
\text { important, but a } \\
\text { bit neglected } \\
\text { Twitter } \\
\text { considered } \\
\text { important to } \\
\text { provide research- } \\
\text { based info/advice, } \\
\text { and to direct } \\
\text { users to their Q } \\
\text { and A page }\end{array}$ & $\begin{array}{l}\text { Limited attention to } \\
\text { SoMe in plans for } \\
\text { epidemics; bland } \\
\text { statement 'will } \\
\text { ensure a full social } \\
\text { media strategy is in } \\
\text { place' } \\
\text { No public } \\
\text { identification of key } \\
\text { SoMe platforms. } \\
\text { Emphasis on } \\
\text { website, especially } \\
\text { NHS Choices; SoMe } \\
\text { used to signpost to } \\
\text { other sources of } \\
\text { information } \\
\text { other sources of } \\
\text { information } \\
\text { SoMe to be used to } \\
\text { communicate with } \\
\text { public rather than } \\
\text { health professionals } \\
\text { and to signpost } \\
\text { on }\end{array}$ & $\begin{array}{l}\text { No evidence that } \\
\text { SoMe is seen as } \\
\text { especially vital. One } \\
\text { of many media } \\
\text { formats and less } \\
\text { important than } \\
\text { some others } \\
\text { Twitter used to } \\
\text { target all audiences; } \\
\text { Linkedin for } \\
\text { professional facing } \\
\text { messages; } \\
\text { Facebook for public } \\
\text { facing messages. } \\
\text { Twitter is primary } \\
\text { social channel } \\
\text { international work } \\
\text { and wider UK effort } \\
\text { poMe used to } \\
\text { professionals; } \\
\text { inform and reassure } \\
\text { public; issue } \\
\text { information to } \\
\text { health }\end{array}$ \\
\hline
\end{tabular}

Norwegian sources: Interviews. UK Sources: PHE 2013, 2014, 2015b; DoH 2012; interview with public health authority. 
Table 1 identifies a clear difference between Norway and the UK. The health authorities in Norway saw social media as increasingly vital channels of communication during crises, and emphasized the importance of giving early advice which could be rapidly updated. Nevertheless, some similarities with the UK are apparent in how this was operationalised, not least in reassuring publics and signposting websites. Although the Norwegian strategy sees social media as creating an opportunity to shape the narrative, the communication directors still consider traditional media a crucial channel for reaching as many as possible. They emphasize using a variety of channels to achieve impact. For the NIPH, Twitter is particularly used to reach health professionals and the media, whereas Facebook is used to advise the general public. The health directorate (NDH) puts more effort into Facebook. The directorate also appointed people from Sierra Leone who were living in Norway to act as opinion leaders and offer advice on preventing the spread of Ebola to Facebook users in West Africa.

Taken together, the two major health authority agencies in Norway attempted to use social media flexibly - and in combination with other media and channels - to communicate about two very different situations. These required different procedures and messages, reflecting different aims: mitigation of public fear of disease spreading nationally, and making information on disease prevention available and effective by using an appropriate tone of voice to target groups in affected African countries. Facebook (but not Twitter) was also used to recruit health professionals to voluntary work in Africa.

Whereas authorities in Norway placed considerable importance on social media, the UK appear to be late adopters. The report into the UK government's handling of swine flu in 2009 concluded that social media had not been used effectively by authorities and needed to be in future health crises (Hine, 2010). However, one confidential interview source suggested that it was only in 2016 - after the Ebola crisis - that the DoH began to 'seriously' address the issue of social media and engage the devolved administrations in developing a UK-wide approach. Instead, greater reliance was placed on the websites, especially 'NHS Choices', and social media was used in part to signpost these. The primacy of websites appears to have been informed by an analysis of their success during the 2009 swine flu pandemic (Hine, 2010) and because of their ability to provide greater clinical detail. The UK saw Twitter as useful for communicating with the general public but not so much health professionals (see also Table 4), while Facebook could engage both the general public and health professionals. Social media does not appear to have been considered for use with local authorities, nor do documents mention the use of a second DoH Twitter account (@DeptHealthPress) apparently geared to providing stories for other more traditional media. 
Table 2: Norwegian and UK health authorities on generating trust through social media.
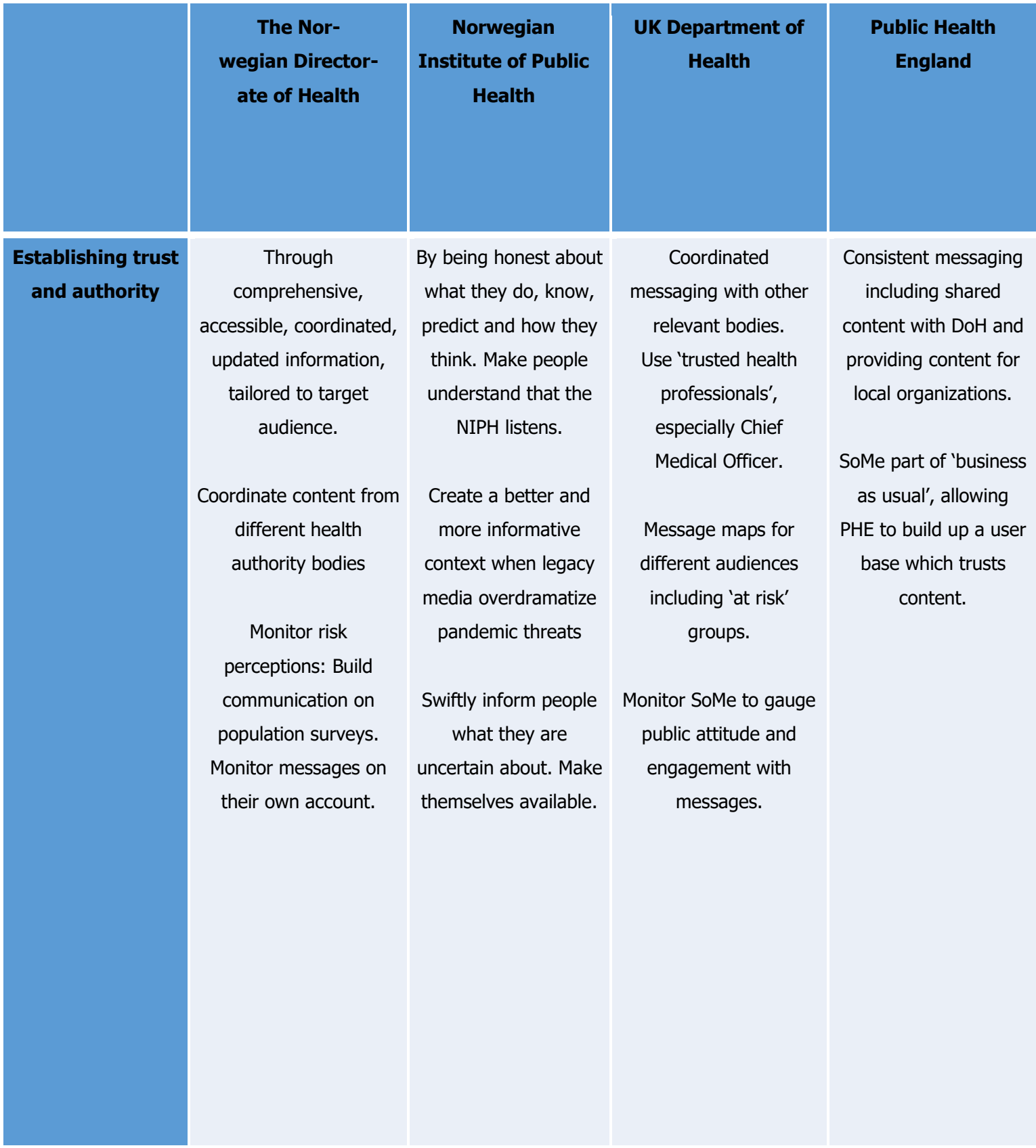

By being honest about

comprehensive,

accessible, coordinated, updated information, tailored to target audience. what they do, know, predict and how they think. Make people understand that the NIPH listens.

Coordinate content from different health authority bodies

Monitor risk perceptions: Build communication on population surveys. Monitor messages on their own account.

\section{Create a better and} more informative context when legacy media overdramatize pandemic threats

Swiftly inform people what they are uncertain about. Make themselves available.
Coordinated

Consistent messaging including shared messaging with other relevant bodies.

Use 'trusted health professionals', especially Chief Medical Officer.

Message maps for different audiences including 'at risk' groups.

Monitor SoMe to gauge public attitude and engagement with messages. content with $\mathrm{DoH}$ and providing content for local organizations.

SoMe part of 'business as usual', allowing

PHE to build up a user base which trusts content.

Norwegian sources: NHD \& NIPH,2014, NHD 2015 a and b, 2016. Interviews. UK Sources: DoH, 2012; UK Government, 2015; PHE, 2013, 2015b; interview with public health authority.

The Norwegian authorities stressed coordination of their messages as vital for building trust during Ebola. The NIPH and the Health Directorate created what was almost a joint information department, to ensure 
comprehensive messages and to 'speak with one voice to people'. Monitoring own citizens' reactions to Ebola was seen as necessary for implementing credible communication initiatives. But they did not monitor general Twitter use to discover public mood and opinion concerning Ebola; rather, they ran a population survey four times. The Norwegian authorities also monitored responses to messages on their own account to see if there were misunderstandings among major actors in society and if people disagreed with or hashtagged them. Both agencies emphasize the importance of understanding the swiftness of social media dissemination for building confidence in health authorities of a country, whereas it weakens trust if they do not make themselves available. Interviews suggested that they believed the latter was the case in Spain, where authorities retrospectively admitted to a reluctance to using Twitter at an early stage of the outbreak, which slowed the process of informing the public. In contrast, Norwegian authorities used Twitter promptly when Silje Lehne Michalsen was medevaced from West Africa (and similarly the UK used Twitter quickly once the Scottish nurse Pauline Cafferkey's infection was made public, though less obviously when the first med-evac, William Pooley, occurred). The NIPH communications director points out the importance of being sincere in social media about what they know and do not know:

We are to be polite and honest. We will respond when someone has any questions about what we do and how we do things. We want people who have sent something to us to understand that we were someone who listened, and we actually do that. There is no reason to be on Twitter if you do not take your followers seriously. (NIPH source in interview 05.04.16)

For NIPH, Twitter enables authorities to provide as many people as possible with 'the full context of the situation', something that traditional media often fail to do, as they 'sort away reservations'; however, the 140 character limit requires them to provide links directing users to web pages for this 'full context'.

In the UK, building trust was important, but the impression given is that social media were not considered an exceptional problem but part of a more general issue in ensuring that messages had an impact upon behavior. Previous experience from health crises - not least VCJD ('mad cow disease') and swine flu, as well as the inconsistent messaging over the safety of the single MMR (measles, mumps and rubella) vaccine - had demonstrated the importance of a coordinated message and of a trusted voice coming from a technical rather than political background. The latter was evidenced during the Ebola crisis, when the UK Chief Medical Officer was widely cited in tweets, and indeed many tweets were identified as originating with her, especially in the key period following the diagnosis of the nurse Pauline Cafferkey. Thus the two key means of establishing trust had little to do with the specific requirements and awareness of social media and more to do with emergency health communications in general. Indeed, policy statements and strategies rarely differentiated between social media and other forms of communication. Nevertheless, some awareness of the specifics of social media were apparent - for example PHE's attempts to build a trusted user base on social media; while subsequent to the Ebola crisis a much more tailored response to social media is being advocated, for example in identifying key influencers ('connectors') on social media to pass messages on, rather than relying on the public to access official feeds 
directly. Regular monitoring of social media took place as a means of assessing public attitudes to the crisis (particularly over the perceived level of risk).

Table 3: UK and Norwegian health authorities' views on flow of information and dynamics of communication in social media during Ebola.
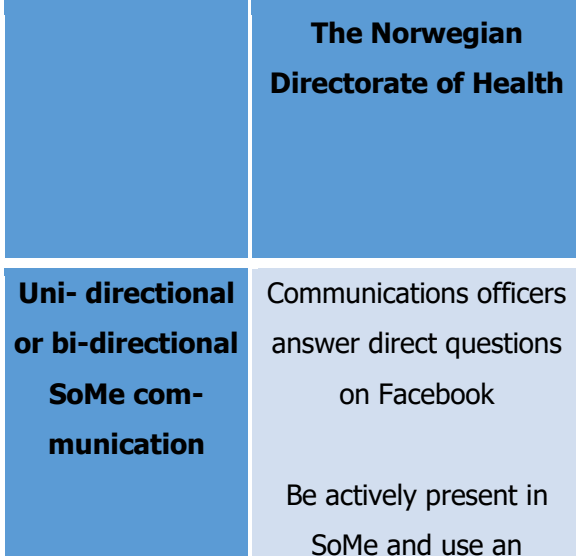

Communications officers answer direct questions on Facebook

Be actively present in

SoMe and use an understandable language .

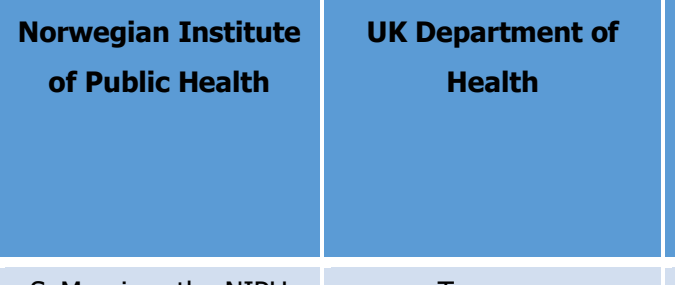

SoMe gives the NIPH opportunity to 'correct misconceptions', 'inform about current knowledge', communicate 'advice on their own terms'

SoMe allows them to 'let people make their own assessments of risk' Listen: Respond to questions. Questions generate spread of more research knowledge

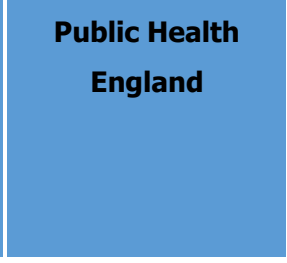

Monitor SoMe communications strategy

- 'positively engaging' with key groups central to strategy.

Weekly analysis of $\mathrm{DoH}$

SoMe as part of analysis of effectiveness of all comms.

\section{Track public awareness through monitoring} SoMe through regular ad hoc 'social/online listening' to 'boost our understanding of questions people were asking on

Twitter or on news websites'.

Listening led to creation of online content in response.

Norwegian sources: NHD \& NIPH,2014, NHD 2015 a and b, 2016. Interviews. UK Sources: PHE 2013, 2014, 2015b; DoH, 2012.

In Norway, health authorities accentuated the dialogical properties of social media communication, particularly in the sense that 'listening' is an important task for them through which they acquire valuable understandings 
of people's reactions, emotions and questions during emerging crises. However, this was less to gain specialist health information than to identify issues of public concern that they have not otherwise responded to:

We get questions we need to answer, the researchers find the information and learn more, and people get more and better information. The more people asked us about Ebola, the longer our questions and answers list became. It was constantly developed and shared on social media. (NIPH source (05.05.16)

Social media, then, adds more pressure to NIPH researchers to seek information. This again enhances communicators' ability to fulfil their objective of 'giving people enough information to make their own assessments' (NIPH interview source, 05.05.16). The effectiveness of the communication is seen as strengthened by not only avoiding professional terminology, but by using a 'fresh' language with 'modern expressions' when appropriate (.ppt-document on social media use in the Health Directorate), thus providing target groups with relevant content. Ultimately, the seemingly bi-directionality of the health authorities' social media communication was mostly a question of obtaining the best possible basis for unidirectional, pandemic risk communication. social media's 'dialogical' communication characteristics were, in other words, viewed as something that enabled effective correction of the public's misconceptions during the outbreak.

In the UK, although monitoring was undertaken to inform online content, this was not so much monitoring of their own accounts as of social media in general. For the DoH, social media was less of a conversation than a public information service. Thus responses to comments on the DoH's Twitter account tended to come from other followers rather than from the DoH itself. Instead, the strategy identified the use of phone lines to deal with individual queries, revealing an assumption that an individual's concerns were likely to be diagnostic (eg 'I feel ill and am afraid I might have.... What do I do?'), rather than the sort of query which tended to appear on Twitter, which ranged from genuine queries over the health risks involved, to critical comments over the government's response (especially perceived over/under-reaction), to more humorous queries (eg whether it was possible to build a wall with Scotland to keep Ebola out). More generally, the DoH strategy was to redirect queries to a website where approved content existed. This reflected an attitude whereby communications were seen as official statements and therefore care had to be taken over them, including obtaining the correct authorisation for any comments. The DoH appeared poorly equipped in terms of procedures to handle the speed of discussion and response on its own Twitter site, a situation perhaps made more difficult by the lack of resources (ie people) assigned to social media in the Department. The strategy to 'positively engage' with key groups, including individuals, does not therefore seem to have applied to social media, while the extent to which the authorities did listen is unclear since the report on social media remains classified (2016b). Nevertheless, there is little or no evidence of the dialogical potential of social media being used. 


\section{Results and analysis 2: use of Twitter by health authorities}

This second part of the analysis schematizes and discusses the health authorities' Twitter postings during Ebola, and also indicates response patterns to tweets with different content topics. The tables provide representations of UK and Norwegian health authorities' self-initiated tweets about Ebola in their most active periods of Twitter communication during the outbreak. The left vertical column of the tables below summarize the different Twitter topics as they were sequentially introduced in the periods. On the horizontal axis, the Twitter content types are specified according the categories identified above. In the tables, we have included specifications of amounts of appearances of 1 . content types, 2 . discourse forms, 3 . dominant speech acts, as well as 4 . total and 5 . average numbers for retweets and favorited tweets, and 6 . tweets that were most retweeted and liked within the different content types.

Table 4: Norwegian health authorities' tweets

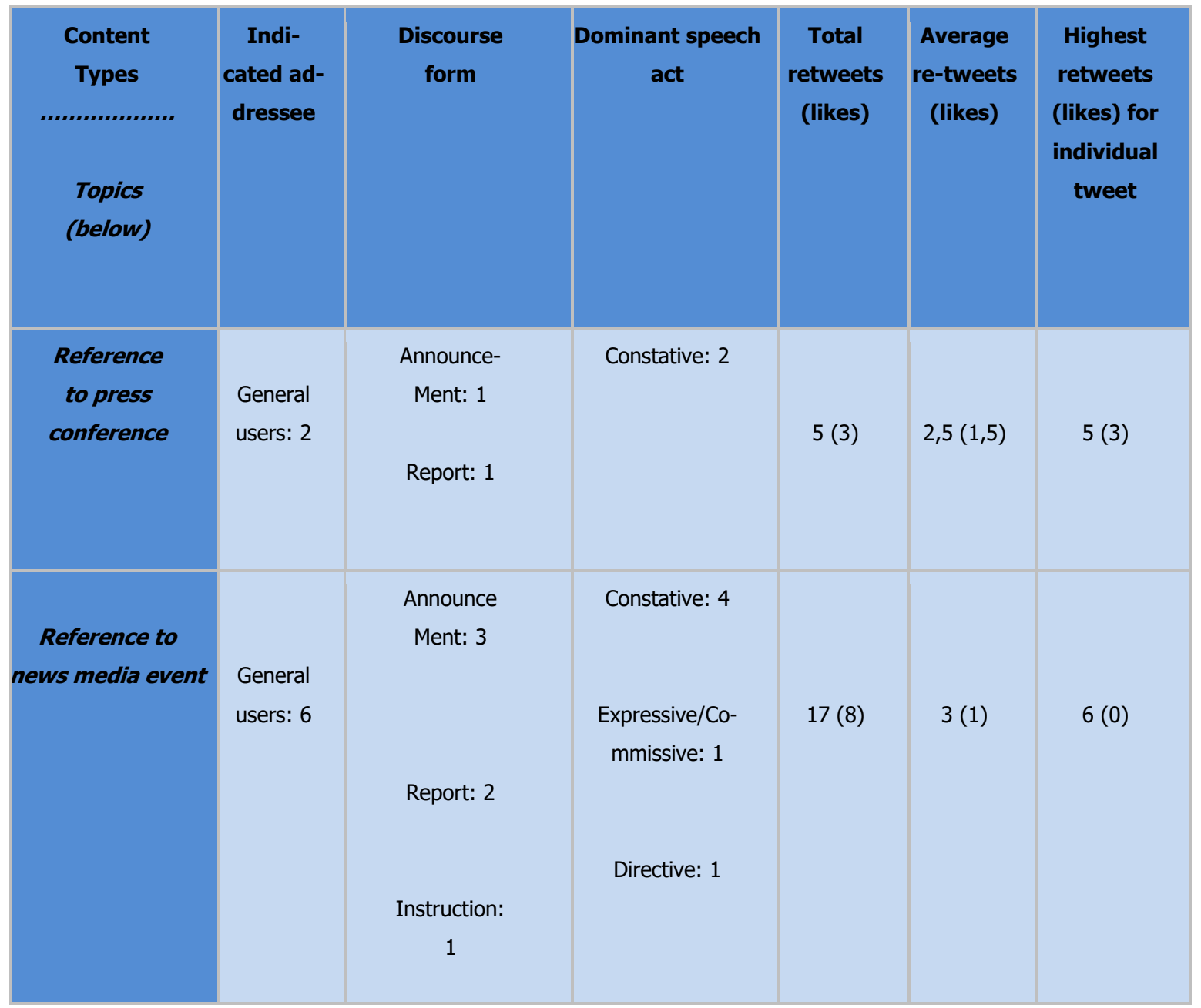




\begin{tabular}{|c|c|c|c|c|c|c|}
\hline $\begin{array}{l}\text { Reference to own } \\
\text { web pages for } \\
\text { public inform- } \\
\text { ation }\end{array}$ & $\begin{array}{l}\text { General } \\
\text { users: } 5\end{array}$ & $\begin{array}{c}\text { Announce } \\
\text { ment: } 3 \\
\text { Announce } \\
\text { ment/Instruction: } 2\end{array}$ & Directive: 5 & $48(12)$ & $10(2)$ & $22(3)$ \\
\hline $\begin{array}{c}\text { Reference to own } \\
\text { web pages' } \\
\text { inform- } \\
\text { ation for health } \\
\text { profession- } \\
\text { als }\end{array}$ & $\begin{array}{c}\text { Health } \\
\text { profes- } \\
\text { sionals: } 4\end{array}$ & $\begin{array}{c}\text { Announce } \\
\text { ment/instruction: } 4\end{array}$ & Directive: 4 & $20(6)$ & $5(1,5)$ & $10(1)$ \\
\hline $\begin{array}{l}\text { Reference to own } \\
\text { seminar }\end{array}$ & $\begin{array}{c}\text { Health } \\
\text { profes- } \\
\text { sionals: } \\
11\end{array}$ & $\begin{array}{l}\text { Instruction: } 1 \\
\text { Announce- } \\
\text { ment: } 3 \\
\text { Report: } 7\end{array}$ & $\begin{array}{l}\text { Directive: } 4 \\
\text { Constative: } 7\end{array}$ & $23(16)$ & $2(1)$ & $3(4)$ \\
\hline
\end{tabular}

Table 4 demonstrates that the health authorities in Norway used Twitter to communicate with health professionals more than did the UK (see table 5). Tweets referring to information on own web pages generated proportionally the most retweets and likes. The amount of these was very low. ${ }^{[5]}$ The low number, however, enabled a closer examination of the professional status of those who responded, revealing that $53 \%$ (60 of 113 ) of those who retweeted have accounts explicitly identifying them as health professionals or health institutions, whereas the same applied to $51 \%$ (23 of 45) of those who favorited the tweets. In other words, much of the Twitter communication during this most intensive 'close to home'-phase of Ebola has a character of being a communication for and among professionals. Tweets relating to a web-broadcast seminar (last vertical column) were particularly popular amongst health workers. While public concern about Ebola had been mitigated by the end of October, communication efforts were channeled towards how health workers were to tackle and prevent spread in outbreak regions of Africa. We detect few instances of Twitter dialogues between general users and the health authorities. In these instances, ${ }^{[6]}$ the authorities' language changes to include expressives and commissives, giving the impression of a more active engagement in users' concerns from the authorities. 
Elsewhere, we only identify such engaged language in a tweet where an authority spokesperson is quoted from a television broadcast, possibly reflecting the spokesperson's adaption to TV broadcast rhetoric.

Directive (14) and Constative (13) speech acts dominate completely, reflecting how the function of the tweets mainly is to guide users to web pages, or to provide factual information. We still question, however, why tweets marked by constatives that directly communicate experts' factual information do not appear before the tweets to health professionals relating to the seminar. Information conveyed in these tweets is based on expert knowledge that the authorities had access to earlier on, and could usefully have been introduced at an earlier stage to lower public concerns. An example: 'How long can \#Ebola survive outside the body? Light and air reduce the life cycle of the virus and reduce the risk for infection'. Such tweets could also have functioned as an interest-provoking alternative to the preferred directives that marked authorities' tweets, such as: 'We remind you that we have a question and answer page about Ebola', followed by an address. This suggests perhaps an initial reluctance to use Twitter as an authoritative communications medium.

Table 5: UK health authorities' tweets

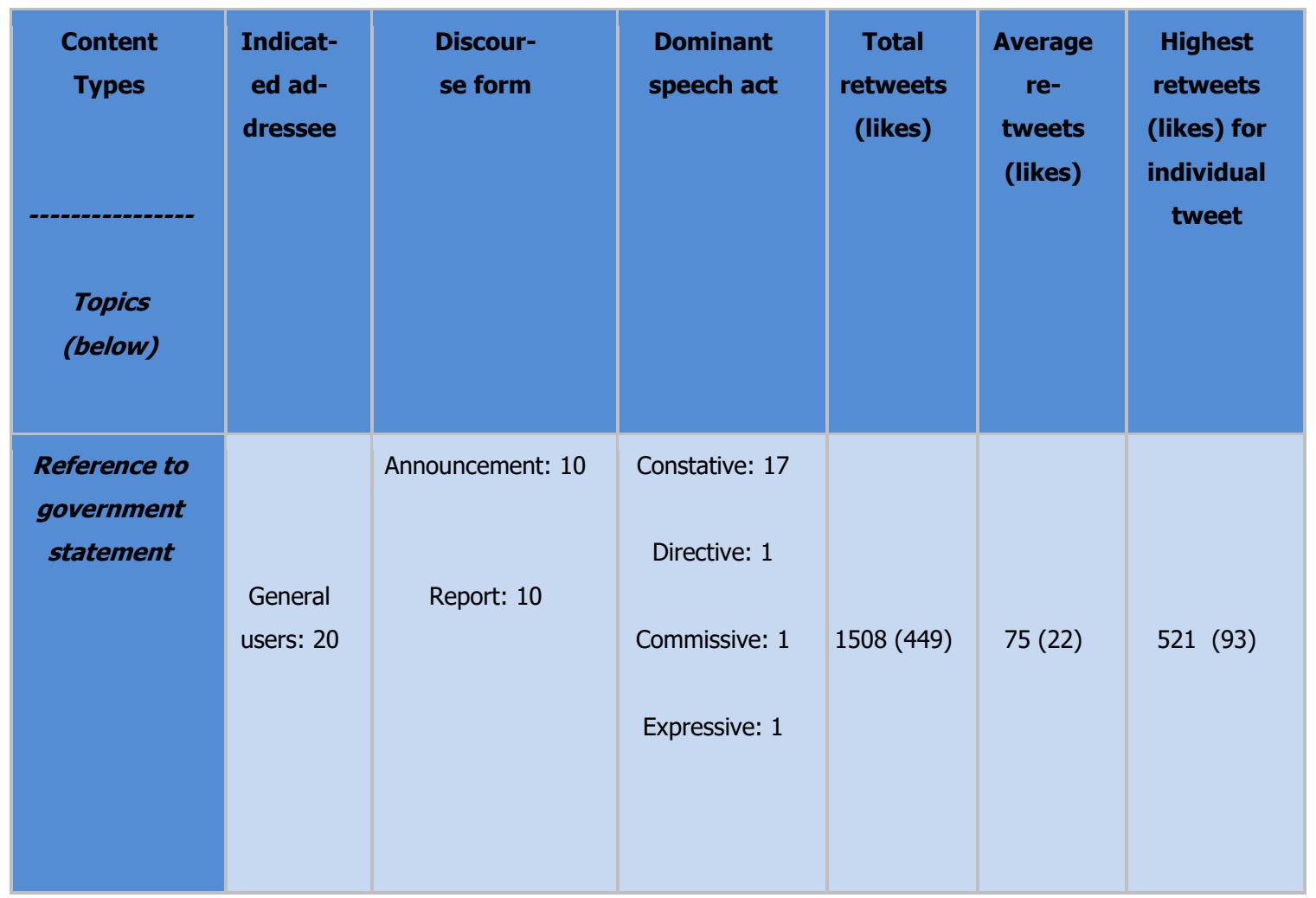




\begin{tabular}{|c|c|c|c|c|c|c|}
\hline $\begin{array}{l}\text { Reference to } \\
\text { news media } \\
\text { event }\end{array}$ & $\begin{array}{l}\text { General } \\
\text { users: } 2\end{array}$ & $\begin{array}{c}\text { Announcement: } 1 \\
\text { Report: } 1\end{array}$ & Constative: 2 & 149 (47) & 75 (24) & $119(39)$ \\
\hline $\begin{array}{l}\text { Reference to } \\
\text { own web pages } \\
\text { (inc youtube) } \\
\text { for public } \\
\text { information }\end{array}$ & $\begin{array}{c}\text { General } \\
\text { users: } 13\end{array}$ & $\begin{array}{l}\text { Instruct- } \\
\text { ion: } 10 \\
\text { Report: } 3\end{array}$ & $\begin{array}{c}\text { Constative: } 7 \\
\text { Directive: } 4 \\
\text { Commissive: } 2\end{array}$ & $478(79)$ & $37(6)$ & $82(15)$ \\
\hline $\begin{array}{l}\text { Reference to } \\
\text { own web pages } \\
\text { for information } \\
\text { for health } \\
\text { professionals }\end{array}$ & $\begin{array}{c}\text { Health } \\
\text { profes- } \\
\text { sionals: } 2\end{array}$ & $\begin{array}{l}\text { Instruct- } \\
\text { ion: } 2\end{array}$ & Directive: 2 & $97(28)$ & $49(14)$ & $75(24)$ \\
\hline $\begin{array}{l}\text { Reference to } \\
\text { other event }\end{array}$ & $\begin{array}{l}\text { General } \\
\text { users: } 4\end{array}$ & $\begin{array}{l}\text { Report: } 2 \\
\text { Other: } 2\end{array}$ & $\begin{array}{l}\text { Constative: } 1 \\
\text { Expressive: } 3\end{array}$ & $130(63)$ & $33(16)$ & $47(25)$ \\
\hline
\end{tabular}

Table 5 clearly reveals the extent to which Twitter was used by the UK Department of Health to communicate with the general public rather than health professionals. It also reveals the extent to which it was used to redirect either to government statements or to other sites run by the UK health authorities. There is a higher number of Reports (16) than Announcements (11) or Instructions (12), but the data set is small - an apparent 33\% increase of Reports over Instructions equates to just 4 tweets - meaning that care should be taken over inferring too much here. In contrast, Constative speech acts constitute by far the greatest number, almost four times the next largest (Directive) which in turn constitute roughly double the number of Commissives and Expressives. Indeed the latter category constitute the smallest grouping of speech acts, revealing that Twitter was used 
overwhelmingly to inform the general public, usually by redirecting them to other sources of information. This is supported by the relatively slight engagement by the DoH with comments on its tweets. Indeed an initial examination suggests that technical queries (eg on symptoms) were answered by other followers rather than the DoH. Interview sources suggested this might in part be due to the unpredictability of some queries and lack of pre-approved content, as well as the brevity imposed by the medium.

Using data on re-tweets and likes as a proxy measure for impact, what is striking is how low the numbers are. The largest by far occurred over the diagnosis of Pauline Cafferkey, when a small flurry of tweets were sent in a very short period of time, many of which led to higher than average re-tweets and likes. This outlier perhaps demonstrates a sensitivity to individual events rather than an ongoing crisis, and especially to major events perceived as risks which are 'near to home'. Nevertheless the contrast with other Twitter accounts is revealing. Most DoH tweets were re-tweeted less than 100 times and received less than 30 likes. This is broadly similar to the number of re-tweets/likes for BBC News (@BBCNews), the top trending news account in the UK with >6M followers; and to tweets sent by Sarah Brown (@SarahBrownUK), the wife of former Prime Minister Gordon Brown who, with 1.23M followers was one of the more popular tweeters on news stories; and the 'social media star' Katie Hopkins (@KTHopkins, 653K followers), whose 29 tweets on Ebola mostly received less than 50 retweets. In contrast the entrepreneur Richard Branson (@richardbranson), another leading user of twitter in the UK with 7.79M followers, received a significantly higher number of re-tweets and likes for his Ebola tweets, while the US health philanthropist Bill Gates (@BillGates) sent 11 tweets, all of which surpassed the DoH's most popular in terms of re-tweets and one of which (a technical point made on 15 October 2014 concerning comparative spread and morbidity of Ebola) was re-tweeted 2834 times. It is also interesting to contrast the large following of these 'twitterati' with the 197,000 of the DoH's main account and the 10,000 of its alternate account, suggesting a lack of penetration by (health) authorities compared to other twitter users. The implication of this is that the UK public is less likely to engage with the health authorities than with a range of other users on social media during a health crisis. Finally, the greatest impact of DoH tweets (measured in terms of retweets and likes) is not the referral to other sources of DoH information, which the UK strategy emphasised; rather it is to Government statements and to other web pages. Referrals to $\mathrm{DoH}$ webpages were $>50 \%$ less effective than any other named categories in our table, the exception being the final category of 'other'.

\section{Conclusions}

The aim of this article was to examine how Norwegian and UK authorities had planned for social media use in health crises, specifically disease outbreaks, and how Twitter was used during the 2014-15 Ebola outbreak. It was prompted by Valentini and Kruckeberg's observation that social media have 'raised questions' over the ability of organizations to respond to the nature of the medium in their crisis communications. Although our analysis broadly supports this observation, we note that whereas the UK's response was sluggish, Norway's was less so and demonstrated greater engagement with the potential of the medium and requirement to change practices. Response therefore was not uniform, suggesting not only the possibility of intervening variables to explain this 
difference but also how a more agile response can be developed. Our analysis also demonstrates some clear differences between UK and Norwegian health authorities, both in terms of the policy and strategies they adopted and the tweets they produced concerning Ebola. Whereas UK authorities paid limited strategic attention to social media and emphasised other forms of communication, Norwegian authorities acknowledged their importance in swiftly providing the public with information to enable risk assessment. Norwegian authorities recognised Twitter's potential as a professional network, whereas UK authorities saw it as most useful for communicating with the general public (with a subsidiary account for the media). The different policies were reflected in the messages they produced. Tweets in the UK were directed to the general public rather than health professionals, while authorities' tweets in Norway, and the responses they generated, clearly indicated how their communication was mainly intended for health professionals. Both the UK and Norway emphasised the importance of coordinated messaging to develop trust, but this is a generalised rather than Twitter-specific strategy.

Our analysis adds to Valentini and Kruckeberg's observation in four important respects: that traditional paradigms of crisis communication not only persist, but remain clearly dominant; that authorities have adapted to using social media as a monitoring tool, but not to its dialogical nature; that authorities' use of social media has not proven especially effective; and that Twitter appears better geared to respond to individual events - such as the diagnosis of Cafferkey - than to long wave events such as a disease outbreak. Strategy documents and interview sources in both UK and Norway emphasized the bi-directionality of social media communication and the importance of listening to establish trust and engage actively and positively with users. There is also evidence of a willingness to alter content based on this listening. However, listening was across social media rather than an engagement with content on their own Twitter feeds. Authorities were less willing to explore social media's distinct interactive communication features. Although some of this reluctance may have been a product of conservatism and a wariness over the new technology, it is nevertheless clear that social media's dialogical character presented challenges to authorities which they did not meet during the Ebola outbreak. Neither Norway nor the UK possessed sufficient capacity to use Twitter as an interactive medium, even on their own posts; authority to respond was not delegated and pre-approved content inherently lacked the flexibility to respond to some queries; and the 140 character limit of Twitter was seen as sufficiently limiting to lead to signposting rather than remaining within the medium itself.

Both UK and Norwegian authorities therefore preferred a vertically integrated approach using Twitter as an information service, with at best minimal opportunities for conversations with the public. In Norway, the few instances of 'dialogues' were preferably a means to correct misconceptions. Constative and directive speech acts, rather than expressives and commissives, characterized the authorities' messages. The dominance of such speech acts in their tweets, supplemented by links to own $\mathrm{Q}$ and $\mathrm{A}$ pages, testified to a detached position and a strategy of directing users to a website where approved content existed. However, retweets and likes from the UK tweets suggest that signposting to other DoH information sources is not especially effective. The comparatively small number of followers to health authorities' Twitter accounts suggests that a key strategy might be to develop a community of trusted users with their own significant base of followers who will pass on 
tweets from health authorities. Interview sources suggest that this approach is now being considered by UK health authorities.

Our overall conclusion is that Twitter has not led to a paradigm shift in crisis communication for health authorities in the UK and Norway, rather to an evolution of practices and policies and adaptation rather than revolution - a practice which might be characterised as 'add Twitter and stir'. Although some might argue that this fails to fully recognise the nature of the medium and exploit its potential, alternatively it does allow authorities to have a consistent approach across multiple media and to build on established practice rather than risk novel strategies in times of crisis when the costs of failure might be high.

\section{References}

Allan, Stuart. 2002. Media, Risk and Science. Buckingham: Open University Press.

Aramaki, Eiji, Sachiko Maskawa, and Mizuki Morita. 2011. "Twitter catches the flu: detecting influenza epidemics using Twitter." Proceedings of the 2011 Conference on Empirical Methods in Natural Language Processing: 1568-1576. http://www.aclweb.org/anthology/D11-1145

Beck, Ulrich (1992) Risk Society: Towards a New Modernity. London: Sage, first published in German in 1986.

Bernardo, Theresa Marie, Andrijana Rajic, Ian Young, Katie Robiadek, Mai T Pham, and Julie A Funk. 2013. "Scoping review on search queries and social media for disease surveillance: a chronology of innovation." J Med Internet Res 2013;15(7):e147. Doi: 10.2196/jmir.2740

Chan, Margaret (2014). 'WHO Director-General's speech to the Regional Committee for the Western Pacific', 13 October 2014, available at http://who.int/dg/speeches/2014/regional-committee-western-pacific/en/ last accessed 15 February 2017.

Chew, Cynthia, and Gunther Eysenbach. 2010. "Pandemics in the Age of Twitter: Content Analysis of Tweets during the 2009 H1N1 Outbreak." PLos One, Vol. 5 (12). doi:10.1371/journal.pone.0014118

Clayforth-Carr, J. 2009. "Pandemic Flu Digital Strategy." Unpublished document prepared for [UK] Department of Health and COI by LBi UK, released to McInnes under FOI request.

Coombs, W. Timothy. 2012. Ongoing Crisis Communication. Los Angeles. Sage.

DoH [Department of Health] [UK]. 2008. Health is Global. London: HMSO.

DoH [UK]. 2012. "UK Pandemic Influenza Communications Strategy." Available at: https://www.gov.uk/government/uploads/system/uploads/attachment data/file/213268/UK-

Pandemic-Influenza-Communications-Strategy-2012.pdf last accessed 22 June 2016.

DoH [UK]. (2016a). Response to Freedom of Information Request FOI-1018712 (McInnes), 10 March.

DoH [UK]. (2016b). Freedom of Information Act Internal Review DH Ref: IR 1029774, 21 June.

Durodie, Bill. 2011. H1N1 - the social cost of elite confusion. Journal of Risk Research Vol 14(5), 511-518.

FCO [Foreign and Commonwealth Office UK]. (2003). UK International Priorities, Cm 6052. London, HMSO. 
Furedi, Frank. 2011. Fear and security: a vulnerability-led perspective. Social Policy and Administration. Vol.42(6), 645-661.

Guardian. 2012. "Twitter now has 10M users in UK." May 15.

Guardian. 2014. "More than one-fifth of Britons will use Twitter this year, claims report." February 2014. February 20.

Hagen, Loni, Thomas Keller, Stephen Neely, Nic DePaula, and Claudia Robert-Cooperman. 2017. Crisis communications in the age of social media: A network analysis of Zika-related tweets. Social Science Computer Review, 1-19. doi: 10.1177/0894439317721985

Hine, Deirdre. 2010. The 2009 Influenza Pandemic - an Independent Review of the UK Response. UK Cabinet Office, 1 July. Available at https://www.gov.uk/government/publications/independent-review-into-theresponse-to-the-2009-swine-flu-pandemic last accessed 17 June 2016.

Hornmoen, Harald, Klas Backholm, Elsebeth Frey, Rune Ottosen, Gudrun Reimerth, and Steen Steensen. 2018. "Key Communicators perspectives on the use of social media in risk and crises." In Robin Andersen and Purnaka L. de Silva (Eds.) (pp. 439-449). The Routledge companion to media and humanitarian action. New York and London: Routledge, Taylor \& Francis Group

Howard, Philip N., Aiden Duffy, Deen Freelon, Muzammil M. Hussain Will Mari, and Marwa Maziad. 2011. "Opening closed regimes: what was the role of social media during the Arab spring?" Available at https://docs.google.com/document/d/1usaCrxWcYMu1z4FzxngMWugUTWZ49weDXEl Q73Aa-Y/edit last accessed October 72016.

Hughes, Amanda L., and Leysia Palen. 2012. The evolving role of the public information officer: An examination of social media in emergency management. Journal of Homeland Security and Emergency Management, 9. doi:10.1515/1547-7355.1976

Johansen, Winni, and Finn Frandsen. 2007. Krisekommunikasjon. Fredriksberg: Forlaget Samfundslitteratur.

Lamb, Alex, Michael J. Paul, and Mark Dredze. 2013. "Separating Fact from Fear: Tracking Flu Infections on Twitter." Conference of the North American Chapter of the Association for Computational Linguistics. HLT-NAACL.789-795.

Latonero, Mark, and Irinia Shklovski. 2011. Emergency management, Twitter, and social media evangelism. International Journal of Information Systems for Crisis Response and Management, 3 (4), 1-16. Retrieved from https://papers.ssrn.com/sol3/papers.cfm?abstract_id=2045863

Luckerson, Victor. 2014. Watch How Word of Ebola Exploded in America. Time 7 October. Available at: http://time.com/3478452/ebola-twitter/ last accessed 17 June 2018.

McInnes, Colin. 2016. "Crisis! What crisis? Global health and the 2014-15 West African Ebola outbreak." Third World Quarterly, 37 (3), 380-400.

Merchant, Raina M., Stacy Elmer, and Nicole Lurie. 201. "Integrating social media into emergency-preparedness efforts." N Eng J Med. 2011, 365 (4): 289-291. doi: 10.1056/NEJMp1103591

Mocanu, Delia, Andrea Baronchelli, Nicola Perra, Bruno Gonçalves, Qian Zhang, Alessandro Vespignani, 2013. 'The Twitter of Babel: Mapping World Languages through Microblogging Platforms', PLoS One available 
at http://journals.plos.org/plosone/article?id=10.1371/journal.pone.0061981 last accessed 13 May 2017.

NHD [Directorate of Health] (Norway) and NIPH [the Norwegian Institute of Public Health]. 2014. "Nasjonal beredskapsplan mot Ebola." [National Contingency Plan against Ebola]. December 2014. NHD [Directorate of Health] (Norway). 2015a. Communication in crisis. 15 May. Released to Hornmoen.

NHD [Directorate of Health] (Norway). 2015b. General points about communication with the public in a pandemic situation. 20151003 Asset-HLPF.

NHD [Directorate of Health] (Norway. 2016. Summary of lessons learned for public health from the Ebola outbreak in West Africa - how to improve preparedness and response in the EU for future outbreaks (our translation). 12 January.

Olson, Donald R., Kevin J. Konty, Marc Paladini, Cecile Viboud, and Lone Simonsen. 2013. "Reassessing Google Flu Trends data for detection of seasonal and pandemic influenza: a comparative epidemiological study at three geographical scales." PLOS Computational Biology, October 17. Available at http://journals.plos.org/ploscompbiol/article?id=10.1371/journal.pcbi.1003256 last accessed 22 June 2016.

Paul, Michael J., and Mark Dredze. 2011. "You Are What You Tweet: Analyzing Twitter for Public Health." In Proc. of the 5th International AAAI Conference on Weblogs and Social Media (ICWSM). http://www.cs.jhu.edu/ mpaul/files/2011.icwsm.twitter health.pdf

Perry, Danielle C., Maureen Taylor, and Marya L. Doerfel. 2003. "Internet-based communication in crisis management." Management Communication Quarterly, 17 (2), 206-233. doi: $10.1177 / 0893318903256227$

PHE [Public Health England].2013. National Incident Response Plan.

PHE. 2014. "Pandemic Influenza Response Plan 2014." Available at: https://www.gov.uk/government/uploads/system/uploads/attachment data/file/344695/PI Response Plan 13 Aug.pdf, last accessed 22 June 2016.

PHE.2015a. Response to Freedom of Information request ref 25/02/sr/618 (McInnes), 13 March.

PHE 2015b. Response to Freedom of Information request ref 12/11/lh/401 (McInnes), 10 December.

Sandman, Peter M. 2014. "Pandemic Flu and Other Infectious Diseases Index". Available at: www.psandman.com/index-infec.htm

Schultz, Friederike, Sonja Utz and Anja Göritz. 2011."Is the medium the message? Perceptions of and reactions to crisis communication via twitter, blogs and traditional media." Public Relations Review (37): s 20-27. https://doi.org/10.1016/j.pubrev.2010.12.001

Searle, John. 1975. "Indirect speech acts." In Syntax and Semantics, vol iii: Speech acts, edited by Peter Cole and Jerry L. Morgan, 59-82. New York: Academic Press.

Simon, Tomer, Avishay Goldberg, Limor Aharonson-Daniel, Dmitry Leykin, and Bruria Adini. 2014. Twitter in the cross fire- the use of social media in the Westgate mall terror attack in Kenya. PLOS One, 9, 1-11. doi: 10.1371/journal.pone.0104136

State Department [US]. 2004. Strategic Plan Fiscal Years 2004-2009. Washington DC: US Department of State. 
Sutton, Jeannette, Leysia Palen, and Irina Shklovski. 2008. "Backchannels on the Front Lines: Emergent Uses of Social Media in the 2007 Southern California Wildfires." In Proceedings of the 5th International ISCRAM Conference - Washington, DC, USA, May, edited by F. Fiedrich and B. Van de Walle. http://www.jeannettesutton.com/uploads/BackchannelsISCRAM08.pdf

Thackeray, Rosemary, Brad L. Neiger, Amanda K. Smith, and Sarah B. Van Wagenen. 2012. "Adoption and use of social media among public health departments." BMC Public Health 2012,12: 242. doi: 10.1186/14712458-12-242

Twitter (2009), "Top Twitter trends of 2009.", available at: https://blog.twitter.com/2009/top-twitter-trends-of2009 last accessed 22 June 2016.

UK Government (2015). "2010-2015 Government policy: health emergency planning." Available at: https://www.gov.uk/government/publications/2010-to-2015-government-policy-health-emergencyplanning/2010-to-2015-government-policy-health-emergency-planning last accessed 22 June 2016.

Utz, Sonja, Friederike Schultz and Sandra Glocka. 2012. "Crisis communication online: How medium, crisis type and emotions affected public reactions in the Fukushima Daiichi nuclear disaster." Public Relations Review. http://dx.doi.orq/10.1016/i.pubrev.2012.09.010

Valentini, Chiara, and Dean Kruckeberg. 2016. "The Future Role of Social Media in International Crisis Communication." In The Handbook of International Crisis Communication Research, edited by Andreas Schwarz, Matthew W. Seeger and Claudia Auer, 478-488. Chichester. Wiley Blackwell

Veil Shari R., Tara Buehner, and Michael J. Palenchar. 2011. A Work-In-Progress Literature Review: Incorporating Social Media in Risk and Crisis Communication. Journal of Contingencies and Crisis Management. (19): 110-122.

Vosoughi, Soroush, and Deb Roy. 2016. "Tweet acts: A speech act classifier for twitter." Proceedings of the 10th AAAI Conference on Weblogs and Social Media ICWSM, 2016. https://arxiv.org/abs/1605.05156

WHO. 2014. "Statement on the 1st meeting of the IHR Emergency Committee on the 2014 Ebola outbreak in West Africa". Available at:http://www.who.int/mediacentre/news/statements/2014/ebola20140808/en/

Zhang, Renxuian, Dehong Gao, and Wenjie Li. 2011. "What Are Tweeters Doing: Recognizing Speech Acts in Twitter." Papers from the 2011 AAAI Workshop on Analyzing Microtext. https://www.aaai.org/ocs/index.php/WS/AAAIW11/paper/viewFile/3803/4337 
[1] Although the World Health Organization did not declare the outbreak over until 2016, by early 2015 the case load had dropped sufficiently that it no longer represented the same level of crisis and much of the attention it had been receiving dissipated.

[2] This of course alludes to Charlotte Bunch's observation concerning gender politics that 'you can't just add women and stir'.

[3] The communications director at NIPH was interviewed 19 November 2014 and 5 April 2016. The communications director at NHD was interviewed at 6 April 2016.

${ }^{[4]}$ The DoH also operated a second Twitter account, @DeptHealthPress. This is not advertised on its website or elsewhere and is therefore unlikely to be the focus of popular attention during an emergency - as suggested by the fact that it currently has just over 10000 followers compared to the main account's 197000 followers. However, this second account does appears to be oriented towards other media and may therefore be indirectly influential when picked up there.

[5] Facebook postings were not schematized and analyzed in this study. However, we note that the general Facebook engagement also was limited. For example, the Norwegian authorities - who emphasize that Facebook is important in advising the general public - had only three postings during the outbreak. The NIPH source believed that the postings had a fairly good reach because of users' sharing (20 sharings at most for a message, our comment). She admitted, though, that they probably still are better at communicating on Twitter than Facebook, where they have to follow their own posts more closely and remove responders' violations of privacy laws.

[6] The 9 instances we detect of such interactivity were initiated by external users, therefore not registered in table 5 . 